\title{
Una nueva Revolución Francesa: La modernización del Code civil
}

Keywords: derecho; legislación; jurisprudencia; animal

Soy una adicta a las lecturas sobre la Revolución Francesa, uno de los acontecimientos centrales para entender el mundo tal como es hoy. Creo haber leído todo lo que se ha escrito sobre el tema y, especialmente los documentos que reflejan las experiencias de quienes vivieron aquellos momentos, me refiero a Memorias, Epistolarios, Crónicas..., pues la Historia, con mayúscula, se escribe por los protagonistas, según el principio "verba, non facta" (las palabras, no los hechos) y lo que hacemos los demás, es reflexionar sobre lo que otros han vivido y experimentado.

Uno de los frutos de la Revolución Francesa, el más permanente y por el que Napoleón sería siempre recordado -según sus propias palabras-, es el Code civil, también llamado Code Napoleon. Un verdadero monumento al pensamiento jurídico, que recogió la tradición romana, vigente en toda Europa como modelo de una sociedad eminentemente agraria y lo transformó en el libro por excelencia del ciudadano: el nuevo hombre, nacido de los postulados revolucionarios. Es sabido que el modelo del Code civil, fue literalmente copiado, con pocas variantes, en toda Europa y Latinoamérica, lo que contribuyó a perpetuar un modelo de sociedad, asentado en la afirmación del hombre y los derechos subjetivos, como eje vertebrador del sistema jurídico. Sería prolijo detallar aquí y ahora, cómo dicho modelo se ha visto sometido a revisión desde diferentes ángulos, que han puesto al descubierto que tal visión ya no resulta apropiada a una sociedad que ha erigido, por ejemplo, al medio ambiente o a las mismas entidades societarias como sujetos de derechos, lo que, radicalmente, pone en cuestión la afirmación del ser humano como centro de todo el sistema jurídico. El Derecho siempre ha tenido en cuenta las realidades sociales cambiantes, para adaptarse a las mismas, para regularlas, en definitiva, para hacer más sencilla y fácil la vida en sociedad. Desde este punto de vista, es claro que la sociedad francesa -sus ciudadanos, sus intelectuales, sus legisladores-, hace tiempo que venían demandando un cambio en algunos ámbitos regulados por el Code civil[1] , que habían quedado obsoletos y ello se ha plasmado en la reciente Ley 2015-177, de 16 de febrero de 2015, relativa a la modernización y simplificación del Derecho y el procedimiento en el ámbito de la justicia y los asuntos internos[2].

La cuestión que me interesa destacar hoy es el cambio del Code civil en relación al estatuto jurídico de los Animales, hasta ahora considerados, como en el resto de los derechos codificados (a excepción de la calificación negativa de los animales como "no-cosas", de Austria, Suiza, Alemania y el Código civil catalán[3]) como cosas en propiedad. La nueva ley ha modificado el art. 515-14, con una nueva redacción más acorde con la condición de los animales como seres vivos dotados de capacidad de sentir. El texto ha quedado redactado de la siguiente forma:

"Les animaux sont des êtres vivants doués de sensibilité ...)"

Esta modificación es de una gran trascendencia, pues posiciona a los animales como seres vivos -no asimilables a las cosas inertes-, diferenciados de las cosas en propiedad y de los seres humanos, a los que su capacidad de sentiencia, les permite gozar de un estatuto jurídico autónomo, mas acorde con lo que la ciencia viene afirmando sobre los animales como "sentient beings", seres sintientes [4] En la expresión francesa: "êtres vivants doués de sensibilité", lo que viene a seguir la línea trazada por la UE en el art. 13 del llamado Tratado de Lisboa (TFUE) y reconocida por destacados organismos internacionales entre los que se encuentra HSI[5]. 
Un resultado tan llamativo y tan trascendente para la historia jurídica europea, ha sido fruto de una amplia e inteligente cooperación entre la sociedad francesa, un grupo de intelectuales, entre los que ha destacado el Prof. Jean Pierre Marguenaud[6], y la Fondation 30 Millions d'Amis, que ha llevado a cabo una campaña de sensibilización y de gestión realmente notable, de lo que se puede calificar con propiedad como un giro histórico[7]. La campaña se abordó desde distintos frentes: se recogieron más de 700.000 firmas de ciudadanos, que abogaban por el reconocimiento jurídico de los animales como seres sintientes, un grupo de 24 intelectuales, de reconocido prestigio, elaboró un Manifiesto, en el que se exponía, que no se solicitaba ningún cambio metafísico sobre la condición de los animales, sino que se les incluyera dentro del ordenamiento jurídico como lo que la ciencia viene subrayando que son: seres capaces de experimentar, dolor, sufrimiento y, por supuesto, alegría. Y, por último, se sensibilizó al legislador francés, mediante la inclusión de esta modificación relativa a los animales, dentro de un proyecto de ley de modernización del Code civil.

El resultado es plenamente satisfactorio y, desde aquí, quisiera felicitar cordialmente a todos los actores que han tomado parte en esta "nueva Revolución Francesa" en favor de los animales. Lo deseable sería que, al igual que con el Code Napoleon, el ejemplo francés fuera el impulso que necesitamos en el sistema jurídico continental, para reconocer a los animales su condición de seres sintientes. El impulso está ahí, ahora nos corresponde a nosotros seguir las mismas pautas "revolucionarias".

LA EDITORA

Teresa Giménez-Candela

Catedrática de Derecho Romano

Directora del Master en Derecho Animal y Sociedad

Directora del SGR Grupo de Investigación ADS

Universitat Autònoma de Barcelona

Sígueme en Facebook: https://www.facebook.com/editora.da

[1] GIMÉNEZ-CANDELA, T., A cara descubierta en favor de los animales: Francia, el 'Code civil' y la Constitución

[2] Loi 2015-177, du 16 février 2015, relative à la modernisation et à la simplification du droit et des procedures dans les domaines de la

justice et des affaires interieures.

[3] GIMÉNEZ-CANDELA, T., A la búsqueda de un régimen jurídico animal.

[4] GIMÉNEZ-CANDELA, T., Seres sintientes.

[5] Vid. The Science of Animal Thinking and Emotion: Sentience as a factor in Policy and Practice

[6] Vid. una sucinta biografía del Prof. Marguenaud

[7] Vid. Un tournant historique. 